\title{
IMPROVEMENT OF THE PYROLYSIS PROCESS
}

\author{
E.R. MAGARIL ${ }^{1,2} \&$ R.Z. MAGARIL ${ }^{2}$ \\ ${ }^{1}$ Ural Federal University, Russia. \\ ${ }^{2}$ Tyumen Industrial University, Russia.
}

\begin{abstract}
In modern chemistry pyrolysis is the principal process and large-tonnage provider, primarily, of lower olefins - ethylene, propylene - as well as butadiene, benzene and other products. The level of efficiency of the pyrolysis process largely determines the development of the petrochemical industry in whole, therefore rationalization of the process is an ongoing task of high relevance.

The aim of this work is to develop a method for increasing the efficiency of the pyrolysis for lower olefins on the base of the analysis of the mechanism of the process with the possibility of controlling it.

The kinetics of the interaction of the hydrocarbons with hydrogen atoms, methyl radicals and their mixtures were determined. The data on the relative reactivity of bonds of different types in reactions with hydrogen atoms and methyl radicals and the data on the effective relative reactivity when using an inert diluent increase our knowledge of the pyrolysis of feedstock of any given composition. A method based on the influence of hydrogen on the thermal reactions of alkanes and alkenes was developed to increase the selectivity of the process for the target product (lower olefins) and to reduce the yield of the liquid products of condensation and specific energy consumption.

Keywords: hydrogen, pyrolysis efficiency, relative reactivity of bonds.
\end{abstract}

\section{INTRODUCTION}

Pyrolysis is the process of high-temperature thermal decomposition performed under not high pressure for a low duration. It has long been studied and these studies are still relevant [1-4]. The processes of pyrolysis of plastic waste and biomass that have been studied over the last decade are, for the most part, catalytic processes [5-7]. The amount of ethylene produced by the pyrolysis of hydrocarbons in 2014 amounted to more than $160 \mathrm{mln}$ tonnes and the production of propylene exceeded $80 \mathrm{mln}$. tonnes [8]. It is predicted that by 2017 , the ethylene production capacity will exceed 200 million tons and propylene production will have increased dramatically. This increases the importance of improving the process of pyrolysis which is the primary source of lower olefin production and determines to a great extent the petrochemical industry's capacity and, for many countries, the capability for industrial production in general. Even a slight increase in product yield, an enhancement of the process selectivity or a reduction in the yield of liquid products of condensation under the current dynamics of ethylene and propylene production will lead to significant savings of scarce hydrocarbons, fuel and other energy resources [4]. It is possible to develop methods to increase the efficiency of pyrolysis once the mechanism of the process is fully understood. However, results of current studies of the pyrolysis mechanism do not provide a complete picture of the process flow. Typically, they are based on laboratory studies of the pyrolysis of individual hydrocarbons, predominantly saturated. Thus, there is an urgent need to study the pyrolysis of unsaturated hydrocarbons, especially olefins. 


\section{DISCUSSION OF THE MECHANISM OF THE PYROLYSIS OF OLEFINS}

Different views on the mechanism of olefins' pyrolysis have been presented in previous studies $[1-3,9]$. Typical reactions for the pyrolysis are the free-radical reactions of hydrocarbons. It is believed that the molecular reactions are also significant [3]. For the radical reactions in the pyrolysis at the chain propagation step, the repetitive reactions regenerating radicals are typical. The influence of the stages of initiation and termination of the chains on the product yield is low, although they can significantly affect the degree of conversion.

A high yield of $\alpha$-olefins at the initial stages of pyrolysis and subsequent reactions with their participation affect the final products' composition. It is known that during the pyrolysis of alkanes the chain-propagation reactions are mostly caused by the hydrogen atom $\dot{H}$ and methyl radical $\dot{C} H_{3}$. The assumption that there is a similar mechanism for the pyrolysis of alkenes results in a conclusion, irrelevant to the experimental data, about the high yield of butadiene according to the reaction (1):

$$
\begin{gathered}
\mathrm{CH}_{2}=\mathrm{CH}-\mathrm{CH}_{2}-\mathrm{CH}_{2}-\mathrm{CH}_{3}+\dot{\mathrm{H}}\left(\dot{\mathrm{C}} \mathrm{H}_{3}\right) \rightarrow \\
\mathrm{CH}_{2}=\mathrm{CH}-\dot{\mathrm{C} H}-\mathrm{CH}_{2}-\mathrm{CH}_{3}+\mathrm{H}_{2}\left(\mathrm{CH}_{4}\right) \rightarrow \mathrm{C}_{4} \mathrm{H}_{6}+\dot{\mathrm{C}} \mathrm{H}_{3}
\end{gathered}
$$

Voevodsky [10] has proposed a mechanism of thermal decomposition of olefins comprising the hypothetical reaction of hydrogen transfer:

$$
\begin{gathered}
\mathrm{CH}_{2}=\mathrm{CH}-\dot{\mathrm{C}} \mathrm{H}-\mathrm{CH}_{2}-\mathrm{CH}_{3}+\mathrm{CH}_{2}=\mathrm{CH}-\mathrm{CH}_{2}-\mathrm{CH}_{2}-\mathrm{CH}_{3} \rightarrow \\
\mathrm{CH}_{2}=\mathrm{CH}-\mathrm{CH}=\mathrm{CH}-\mathrm{CH}_{3}+\mathrm{CH}_{3}-\dot{\mathrm{C}} \mathrm{H}-\mathrm{CH}_{2}-\mathrm{CH}_{2}-\mathrm{CH}_{3}
\end{gathered}
$$

Kinetic analysis of the mechanism proposed by Voevodsky showed its incorrectness and it was suggested that the addition reactions of the leading chain radicals through $\pi$ bonds $[11,12]$ would proceed by the following type of reaction:

$$
\dot{\mathrm{H}}+\mathrm{CH}_{2}=\mathrm{CH}-\mathrm{CH}_{2}-\mathrm{CH}_{2}-\mathrm{CH}_{3} \rightarrow \mathrm{CH}_{3}-\dot{\mathrm{C}} \mathrm{H}-\mathrm{CH}_{2}-\mathrm{CH}_{2}-\mathrm{CH}_{3}
$$

The mechanism of the olefins' pyrolysis described by reaction (3) allows one to predict the composition of pyrolysis products. However, it remains necessary to carry out more in-depth experimental studies.

\section{RELATIVE REACTIVITY OF C-H BONDS IN THE PYROLYSIS}

The process of pyrolysis proceeds through the radical-chain mechanism whereby the chains are propagated by the hydrogen atoms and methyl radicals. The type of radicals formed is defined by the correlation of relative reactivity of the various $\mathrm{C}-\mathrm{H}$ bonds and the subsequent decay of the radicals formed determines the composition of the pyrolysis products. A great deal of work has been undertaken by the authors to determine the relative reactivity of the $\mathrm{C}-\mathrm{H}$ bonds in the hydrocarbon molecules in reactions with the hydrogen atoms and methyl radicals. The pyrolysis was carried out at $993-1073 \mathrm{~K}$ under atmospheric pressure. The reactions proceeded in quartz tubes of small diameter placed in a tube furnace. The products were analyzed by the chromatography method. Three variations of the pyrolysis process were carried out using different diluents: the hydrocarbon mixture was diluted with hydrogen, with an inert gas (helium) and with helium with the addition of $60 \mathrm{~mol} \%$ of propylene into the hydrocarbon mixture. 
In the case of dilution with helium and added propylene the hydrogen atoms reacted with propylene and were substituted by the methyl radicals which made it possible to determine the relative reactivity of different types of bonds in interaction with $\mathrm{CH}_{3}$.

In the case of dilution with hydrogen, the methyl radicals were substituted by the hydrogen atoms and the relative reactivity of different types of bonds in interaction with the hydrogen atoms was able to be determined. In the case of dilution with helium, the hydrogen atoms and methyl radicals reacted jointly and the effective relative reactivity - the reactivity of the bonds relative to the mixture of methyl radicals and hydrogen atoms - could be determined.

This approach allowed the authors to determine the kinetics of the interaction of hydrocarbons with the hydrogen atoms, methyl radicals and mixtures thereof. A ratio of rate constants of the pyrolysis of molecules in a mixture is defined by the ratio of the sums of the relative activities of $\mathrm{C}$ - $\mathrm{H}$ bonds in the molecules. For example, in the pyrolysis of the mixture containing propane and n-butane the ratio of the rate constant of decomposition for butane to that of propane is equal to $\frac{1 \cdot 6+x \cdot 4}{1 \cdot 6+x \cdot 2}$, where 1 is the relative reactivity of $C-H$ bond in the methyl group and $\mathrm{x}$ is the relative reactivity of $\mathrm{C}-\mathrm{H}$ bond in $\mathrm{CH}_{2}$ groups. To determine the relative reactivity of the $\mathrm{C}-\mathrm{H}$ bond conjugated with the double bond, the authors carried out the pyrolysis of a mixture of tetralin with propane. As a result, the value of the relative reactivity of the $\mathrm{C}-\mathrm{H}$ bond conjugated with the double bond in the case of dilution with hydrogen was found to be equal to 2 , in the case of dilution with helium - equal to 5 and in the case of dilution with helium and the addition of propylene -equal to 8 . Table 1 presents the relative reactivity of different types of bonds obtained as a result of studies of many hydrocarbon mixtures.

\section{INVESTIGATION OF THE MECHANISM OF INDIVIDUAL REACTIONS OF OLEFINS IN THE PYROLYSIS}

The authors studied the pyrolysis of the mixture of pentene- 1 with propane. The pyrolysis was carried out under overall atmospheric pressure at a temperature of $963 \mathrm{~K}$ and a molar ratio of the components $\left[\mathrm{C}_{3} \mathrm{H}_{8}\right]:\left[\mathrm{C}_{5} \mathrm{H}_{8}\right]:$ [diluent] equal to $2 \div 3: 2 \div 10: 87 \div 96$. The results are shown in Table 2.

From the table, it can be seen that the replacement of the inert diluent by hydrogen greatly enhances the addition reaction of hydrogen over the $\pi$ bond (4):

$$
\begin{gathered}
\dot{\mathrm{H}}+\mathrm{CH}_{2}=\mathrm{CH}-\mathrm{CH}_{2}-\mathrm{CH}_{2}-\mathrm{CH}_{3} \rightarrow \mathrm{CH}_{3}-\dot{\mathrm{C}} \mathrm{H}-\mathrm{CH}_{2}-\mathrm{CH}_{2}-\mathrm{CH}_{3} \rightarrow \\
\rightarrow \mathrm{C}_{3} \mathrm{H}_{6}+\dot{\mathrm{C}}_{2} \mathrm{H}_{5}
\end{gathered}
$$

and suppresses the reactions of butadiene formation:

$$
\begin{gathered}
\mathrm{CH}_{2}=\mathrm{CH}-\mathrm{CH}_{2}-\mathrm{CH}_{2}-\mathrm{CH}_{3}+\dot{\mathrm{H}}\left(\mathrm{CH}_{3}\right) \rightarrow \mathrm{CH}_{2}=\mathrm{CH}-\dot{\mathrm{C}} \mathrm{H}-\mathrm{CH}_{2}-\mathrm{CH}_{3}+\mathrm{H}_{2}\left(\mathrm{CH}_{4}\right) \rightarrow \\
\rightarrow \mathrm{C}_{4} \mathrm{H}_{6}+\dot{\mathrm{C}} \mathrm{H}_{3}
\end{gathered}
$$

Knowledge of the relative reactivity of different types of bonds in the hydrocarbon molecules may provide insight into the mechanism of the reactions of individual hydrocarbons.

For example, in the case of the pyrolysis of pentene-1 diluted with hydrogen, the reaction mechanism is described by the following scheme:

$$
\begin{aligned}
\dot{\mathrm{H}}+\mathrm{CH}_{2}=\mathrm{CH}-\mathrm{CH}_{2} & -\mathrm{CH}_{2}-\mathrm{CH}_{3} \rightarrow \mathrm{CH}_{3}-\dot{\mathrm{CH}}-\mathrm{CH}_{2}-\mathrm{CH}_{2}-\mathrm{CH}_{3} \rightarrow \\
& \rightarrow \mathrm{C}_{3} \mathrm{H}_{6}+\dot{\mathrm{C}}_{2} \mathrm{H}_{5}
\end{aligned}
$$


Table 1: Relative reactivity of bonds.

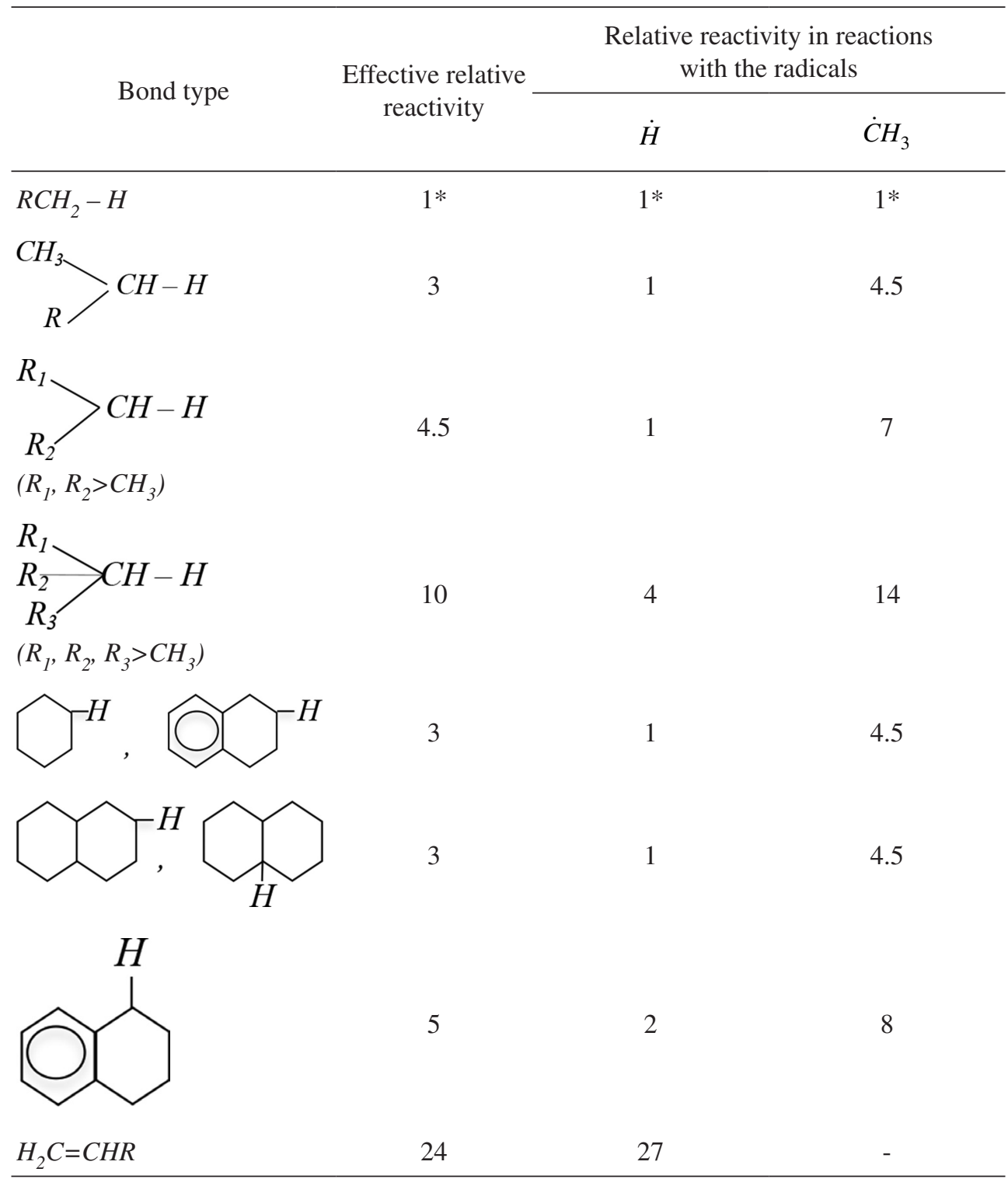

*accepted.

$$
\begin{gathered}
\dot{\mathrm{H}}+\mathrm{CH}_{2}=\mathrm{CH}-\mathrm{CH}_{2}-\mathrm{CH}_{2}-\mathrm{CH}_{3} \rightarrow \mathrm{H}_{2}+\mathrm{CH}_{2}=\mathrm{CH}-\mathrm{CH}_{2}-\mathrm{CH}_{2}-\dot{\mathrm{C}} \mathrm{H}_{2} \rightarrow \\
\rightarrow \mathrm{C}_{2} \mathrm{H}_{4}+\dot{\mathrm{C}}_{3} \mathrm{H}_{5} \\
\dot{\mathrm{H}}+\mathrm{CH}_{2}=\mathrm{CH}-\mathrm{CH}_{2}-\mathrm{CH}_{2}-\mathrm{CH}_{3} \rightarrow \mathrm{H}_{2}+\mathrm{CH}_{2}=\mathrm{CH}-\mathrm{CH}_{2}-\dot{\mathrm{CH}}-\mathrm{CH}_{3} \rightarrow \\
\mathrm{CH}_{2}=\mathrm{CH}-\mathrm{CH}=\mathrm{CH}-\mathrm{CH}_{3}+\dot{\mathrm{H}}
\end{gathered}
$$


Table 2: Products resulting from the pyrolysis of the mixture of pentene-1 with propane at 963 $\mathrm{K}$ under overall atmospheric pressure (mol per mol of the decomposed pentene-1).

\begin{tabular}{ccc}
\hline Product & Pyrosylis in helium & Pyrolysis in hydrogen \\
\hline $\mathrm{C}_{3} \mathrm{H}_{6}$ & 127.5 & 176.3 \\
$\mathrm{C}_{4} \mathrm{H}_{6}$ & 75.3 & 40.3 \\
\hline
\end{tabular}

$$
\begin{gathered}
\dot{\mathrm{H}}+\mathrm{CH}_{2}=\mathrm{CH}-\mathrm{CH}_{2}-\mathrm{CH}_{2}-\mathrm{CH}_{3} \rightarrow \mathrm{H}_{2}+\mathrm{CH}_{2}=\mathrm{CH}-\dot{\mathrm{C}} \mathrm{H}-\mathrm{CH}_{2}-\mathrm{CH}_{3} \rightarrow \\
\rightarrow \mathrm{CH}_{2}=\mathrm{CH}-\mathrm{CH}=\mathrm{CH}_{2}+\dot{\mathrm{C}} \mathrm{H}_{3}
\end{gathered}
$$

The relative reactivity of pentene- 1 in the pyrolysis in hydrogen was estimated based on the data on the relative reactivity of different types of bonds, shown in Table 1, and the number of these bonds, and is equal to $27 \cdot 1+2 \cdot 2+1 \cdot 2+3 \cdot 1=36$.

Contribution of the reactions $6-9$ in this case is described by the ratio (\%): $75: 8.3$ : 5.6: 11.1 .

For pentene-1 diluted with helium, the pyrolysis mechanism is described by the same scheme with a change in the contribution of the reactions. The relative reactivity of pentene- 1 in the inert diluent is $24 \cdot 1+5 \cdot 2+3 \cdot 2+1 \cdot 3=43$. The contribution of the reactions $6-9$ is described by the ratio (\%): $55.8: 7: 14: 23.2$.

Thus, during pyrolysis in an inert diluent, decay of pentene- 1 through the addition reaction over the $\pi$ bond occurs to a much lesser extent than that in hydrogen. The atoms joined to $\pi$ bonds were predominantly hydrogen atoms.

These findings were confirmed by the results of pyrolysis of other hydrocarbon mixtures.

In the pyrolysis of the mixture of butene- 1 with n-butane (1: 1) at $993 \mathrm{~K}$, the yield of ethylene under dilution with helium amounted to $80.6 \mathrm{~mol}$ per total amount of the decomposed hydrocarbons (mol), when diluted with hydrogen it amounted to $89.6 \mathrm{~mol} / \Sigma \mathrm{mol}$. This was due to an increase of up to $79.4 \%$ of the share of butene- 1 decomposed through the addition over the $\varpi$ bond when using hydrogen as a diluent (in the pyrolysis in an inert diluent $-64.9 \%$ ).

The results obtained show that when using hydrogen as a diluents the yield of lower olefins - target products of the pyrolysis - increases due to the addition of a hydrogen atom to the $\pi$ bond of alkenes of $\mathrm{C}_{4}$-type and higher and the formation of butadiene decreases.

As has been shown by the authors earlier [13], the significantly lower selectivity of C-H bonds of different types in interaction with hydrogen atoms than that with methyl radicals causes an increased ethylene yield from the pyrolysis. Moreover, hydrogen inhibits condensation of the ethylene.

The partial replacing of steam by hydrogen in the ratio of 9:1 when used as a diluent of feedstock in the pyrolysis process improves the process selectivity for lower olefins due to the influence of hydrogen on the thermal reactions of alkanes and alkenes. The minimum amount of hydrogen required is about $2 \mathrm{wt} \%$. Also, the specific consumption of thermal energy for the production of ethylene and propylene [14] reduces and, consequently, production costs reduce.

\section{CONCLUSION}

The values of the relative reactivity of $\mathrm{C}-\mathrm{H}$ bonds of different types in interaction with hydrogen atoms and methyl radicals and the effective relative reactivity of raw materials when 
diluted with an inert diluent were obtained. Using these data makes it possible to increase the knowledge of the pyrolysis of the raw material of any given composition and allows one to control the efficiency of the process.

The $\mathrm{n}$ bonds in the addition reactions of hydrogen atoms were shown to possessa high relative reactivity which, when adding hydrogen as a diluent, results in the preferential conversion of alkenes $\mathrm{C}_{4+}$ into the target pyrolysis products and lessens the formation of butadiene and, therefore, liquid products of its condensation, significantly increasing the efficiency of the process.

\section{ACKNOWLEDGEMENTS}

This research was supported by Act 211 Government of the Russian Federation, contract № 02.A03.21.0006.

\section{REFERENCES}

[1] Albright, L., Crynes, B. \& Corcoran, W., Pyrolysis: Theory and Industrial Practice, Academic Press: New York, 1983.

[2] Sundara, K. \& Froment, G., Modeling of thermal cracking kinetics. 3. Radical mechanisms for the pyrolysis of simple paraffins, olefins, and their mixtures. Industrial and Engineering Chemistry Fundamentals, 17, pp. 174-182, 1978. http://dx.doi.org/10.1021/i160067a006

[3] Sadrameli, S.M., Thermal/catalytic cracking of hydrocarbons for the production of olefins: a state-of-the-art review I: thermal cracking review. Fuel, 140, pp. 102-115, 2015. http://dx.doi.org/10.1016/j.fuel.2014.09.034

[4] Wang, X.Q., Xie, C.G., Li, Z.T. \& Zhu, G.Q., Catalytic processes for light olefin production. (Chapter 5). Practical Advances in Petroleum Processing, eds. C.S. Hsu \& P.R. Robinson, Springer Science - Business Media, Inc.: New York, Vol. 1, pp. 149-168, 2006.

[5] Lewandowski, W.M., Radziemska, E., Ryms, M. \& Ostrowski, P., Modern methods of thermochemical biomass conversion into gas, liquid and solid fuels. Ecological Chemistry and Engineering, 18(1), pp. 39-47, 2011.

[6] Grigiante, M., Ischia, M., Baratieri, M., Maschio, R.D. \& Ragazzi, M., Pyrolysis analysis and solid residue stabilization of polymers, waste tyres, spruce sawdust and sewage sludge. Waste and Biomass Valorization, 1(4), pp. 381-393, 2010. http://dx.doi.org/10.1007/s12649-010-9038-2

[7] Rezaei, P.S., Shafaghat, H. \& Daud, W.M.A.W., Production of green aromatics and olefins by catalytic cracking of oxygenate compounds derived from biomass pyrolysis: a review. Applied Catalysis A: General, 469, pp. 490-511, 2014. http://dx.doi.org/10.1016/j.apcata.2013.09.036

[8] http://www.globaldata.com

[9] Belohlav, Z., Zamostny, P. \& Herink, T., The kinetic model of thermal cracking for olefins production. Chemical Engineering and Processing, 42(6), pp. 461-473, 2003. http://dx.doi.org/10.1016/S0255-2701(02)00062-4

[10] Voevodsky, V.V., Issues of Chemical Kinetics, Catalysis and Reactivity, [in Russian], Izv Acad. Nauk USSR: Moscow, 1955.

[11] Magaril, R.S., Some problems of the cracking mechanism of the hydrocarbons. Symposium on Refining Petroleum for Chemicals. Preprints, American Chemical Society: New York, 14(4), pp. D68-D75, 1969. 
[12] Magaril, R.S., Some problems of the cracking mechanism of the hydrocarbons. refining petroleum for chemicals (Chapter 6). Advances in Chemistry Series, eds L.J. Spillone \& H.P. Leftin, American Chemical Society: New York, 97, pp. 110-122, 1970.

[13] Magaril, E. \& Magaril, R., Increasing the selectivity of the hydrocarbon feedstock pyrolysis. WIT Transactions on Ecology and the Environment, WIT Press: UK, 186, pp. 529-534, 2014.

[14] Demidenko, M., Magaril, R. \& Magaril, E., Aqueous vapour substitution for hydrogen in the process of pyrolysis. WIT Transactions on Ecology and the Environment, 190(2), WIT Press, UK, pp. 855-860, 2014. 